Eixo Temático: História e Filosofia da Biologia

\title{
ET-03-001
}

\section{O DIREITO DOS ANIMAIS: UMA INTRODUÇÃO}

Ronilson José da Paz

Instituto Brasileiro do Meio Ambiente e dos Recursos Naturais Renováveis - IBAMA. Av. Dom Pedro II, 3284. Torre. João Pessoa-PB (CEP 58040-915). E-mail:ronilson.paz@gmail.com.

http://dx.doi.org/10.21472/congrebio2016.et-03-001

\section{RESUMO}

O presente trabalho faz uma breve análise da legislação federal brasileira sob a óptica dos direitos dos animais. Observa-se que o mencionado corpo normativo, embora, por evidente, essencialmente construído com uma visão antropocêntrica, contém avanços significativos e capazes de tutelar de maneira eficiente, se não todos, pelo menos alguns direitos significativos dos animais.

Palavras-chaves: Fauna; Proteção da fauna silvestre; Crimes ambientais.

\section{INTRODUÇÃO}

A relação do Homo sapiens com os animais sempre foi do tipo predador e presa, movida pelas leis naturais da sobrevivência, inclusive a visão bíblica considerando os animais como criaturas brutas e desprovidas de alma ou intelecto, afastou-lhes da esfera das preocupações morais humanas (LEVAI, 2004). Graças a essa concepção, a crença de que toda arvorem rio, montanha ou outro objeto natural tinha seu espírito guardião foi desfeita (CROALL e RANKIN, 1981), sendo considerado pecado o paganismo (HIGGINBOTHAM e HIGGINBOTHAM, 2003). Sem a alma que lhes pudessem proteger, os animais poderiam ser dizimados sem qualquer tipo de preocupação ou remorso.

Quem chamou a atenção do clero sobre a necessidade de considerar a igualdade de todas as espécies da biosfera foi São Francisco de Assis, sendo considerado patrono da Ecologia pelo Papa João Paulo II, em 1980 (CROALL e RANKIN, 1981; LEVAI, 2004).

Embora com consequências nefastas para São Francisco de Assis, que foi colocado para fora da Igreja, o alerta foi captado e através da criação do Direito Ambiental, com o objetivo de promover a proteção do meio ambiente, regulando as atividades humanas efetiva ou potencialmente causadoras de impacto sobre o meio ambiente, com o intuito de defendê-lo, melhorá-lo e de preservá-lo para as gerações futuras (FARIAS, 2009).

Tendo em vista a característica extremamente peculiar dos Homo sapiens de transformar drasticamente o ambiente natural em que vivem ou não (HARARI, 2016), foi necessária a imposição de regras, normas e leis à sociedade para que garantissem a sobrevivência da espécie humana e de outras espécies na Terra.

\section{OBJETIVOS}

Este trabalho tem como objetivo discorrer sobre os direitos dos animais contidos na legislação ambiental federal no Brasil. 


\section{PROTEÇÃO LEGAL DOS ANIMAIS NO BRASIL}

A proteção legal da fauna no Brasil teve início com a promulgação da Lei no 5.197/1967 (BRASIL, 1967), que, além de revogar o Decreto-Lei no 5.894/1943 (BRASIL, 1943), que anteriormente permitia o exercício da caça profissional em todo o território nacional, declarou que os animais de quaisquer espécies, em qualquer fase do seu desenvolvimento e que vivem naturalmente fora do cativeiro, constituindo a fauna silvestre, bem como seus ninhos, abrigos e criadouros naturais são propriedades do Estado, sendo proibida a sua utilização, perseguição, destruição, caça ou apanha, além de proibir o exercício da caça profissional (BRASIL, 1967).

Com a promulgação da Lei dos Crimes Ambientais (Lei $n^{\circ}$ 9.605/1998), houve a imposição das sanções administrativas e penais para as condutas e atividades lesivas ao meio ambiente, no que se refere aos crimes contra a fauna, contra flora, por poluição ambiental, por crimes contra o ordenamento urbano e o patrimônio cultural, bem como por crimes contra a administração ambiental (BRASIL, 1998).

Com relação à proteção à fauna, a Lei $n^{0}$ 9.605/1998 é exaustiva e prevê várias ações que podem comprometer à biodiversidade faunística (arts. 29 a 36), incluindo os maus-tratos (art. 32), os campos naturais de invertebrados aquáticos (art. 33, II), os bancos de moluscos ou corais (art. 33, III), além dos pescados (art. 34 a 36):

Art. 29. Matar, perseguir, caçar, apanhar, utilizar espécimes da fauna silvestre, nativos ou em rota migratória, sem a devida permissão, licença ou autorização da autoridade competente, ou em desacordo com a obtida:

Pena - detenção de seis meses a um ano, e multa.

$\S 1^{\circ}$ Incorre nas mesmas penas:

I - quem impede a procriação da fauna, sem licença, autorização ou em desacordo com a obtida;

II - quem modifica, danifica ou destrói ninho, abrigo ou criadouro natural;

III - quem vende, expõe à venda, exporta ou adquire, guarda, tem em cativeiro ou depósito, utiliza ou transporta ovos, larvas ou espécimes da fauna silvestre, nativa ou em rota migratória, bem como produtos e objetos dela oriundos, provenientes de criadouros não autorizados ou sem a devida permissão, licença ou autorização da autoridade competente.

$\S 2^{\circ}$ No caso de guarda doméstica de espécie silvestre não considerada ameaçada de extinção, pode o juiz, considerando as circunstâncias, deixar de aplicar a pena.

$\S 3^{\circ}$ São espécimes da fauna silvestre todos aqueles pertencentes às espécies nativas, migratórias e quaisquer outras, aquáticas ou terrestres, que tenham todo ou parte de seu ciclo de vida ocorrendo dentro dos limites do território brasileiro, ou águas jurisdicionais brasileiras.

$\S 4^{\circ}$ A pena é aumentada de metade, se o crime é praticado:

I - contra espécie rara ou considerada ameaçada de extinção, ainda que somente no local da infração;

II - em período proibido à caça;

III - durante a noite;

IV - com abuso de licença;

$\mathrm{V}$ - em unidade de conservação;

VI - com emprego de métodos ou instrumentos capazes de provocar destruição em massa.

$\S 5^{\circ}$ A pena é aumentada até o triplo, se o crime decorre do exercício de caça profissional.

$\S 6^{\circ}$ As disposições deste artigo não se aplicam aos atos de pesca.

Art. 30. Exportar para o exterior peles e couros de anfíbios e répteis em bruto, sem a autorização da autoridade ambiental competente:

Pena - reclusão, de um a três anos, e multa. 
Art. 31. Introduzir espécime animal no País, sem parecer técnico oficial favorável e licença expedida por autoridade competente:

Pena - detenção, de três meses a um ano, e multa.

Art. 32. Praticar ato de abuso, maus-tratos, ferir ou mutilar animais silvestres, domésticos ou domesticados, nativos ou exóticos:

Pena - detenção, de três meses a um ano, e multa.

$\S 1^{\circ}$ Incorre nas mesmas penas quem realiza experiência dolorosa ou cruel em animal vivo, ainda que para fins didáticos ou científicos, quando existirem recursos alternativos.

$\S 2^{\circ}$ A pena é aumentada de um sexto a um terço, se ocorre morte do animal.

Art. 33. Provocar, pela emissão de efluentes ou carreamento de materiais, o perecimento de espécimes da fauna aquática existentes em rios, lagos, açudes, lagoas, baías ou águas jurisdicionais brasileiras:

Pena - detenção, de um a três anos, ou multa, ou ambas cumulativamente.

Parágrafo único. Incorre nas mesmas penas:

I - quem causa degradação em viveiros, açudes ou estações de aqüicultura de domínio público;

II - quem explora campos naturais de invertebrados aquáticos e algas, sem licença, permissão ou autorização da autoridade competente;

III - quem fundeia embarcações ou lança detritos de qualquer natureza sobre bancos de moluscos ou corais, devidamente demarcados em carta náutica.

Art. 34. Pescar em período no qual a pesca seja proibida ou em lugares interditados por órgão competente:

Pena - detenção de um ano a três anos ou multa, ou ambas as penas cumulativamente.

Parágrafo único. Incorre nas mesmas penas quem:

I - pesca espécies que devam ser preservadas ou espécimes com tamanhos inferiores aos permitidos;

II - pesca quantidades superiores às permitidas, ou mediante a utilização de aparelhos, petrechos, técnicas e métodos não permitidos;

III - transporta, comercializa, beneficia ou industrializa espécimes provenientes da coleta, apanha e pesca proibidas.

Art. 35. Pescar mediante a utilização de:

I - explosivos ou substâncias que, em contato com a água, produzam efeito semelhante;

II - substâncias tóxicas, ou outro meio proibido pela autoridade competente:

Pena - reclusão de um ano a cinco anos.

Art. 36. Para os efeitos desta Lei, considera-se pesca todo ato tendente a retirar, extrair, coletar, apanhar, apreender ou capturar espécimes dos grupos dos peixes, crustáceos, moluscos e vegetais hidróbios, suscetíveis ou não de aproveitamento econômico, ressalvadas as espécies ameaçadas de extinção, constantes nas listas oficiais da fauna e da flora.

As bases legais para o enquadramento dos comportamentos adotados com os animais que podem ser caracterizados como maus-tratos foram determinados pelo Decreto $n^{\circ}$ 24.645/1934 (BRASIL, 1934):

Art. $3^{\circ}$ Consideram-se maus tratos:

I - praticar ato de abuso ou crueldade em qualquer animal;

II - manter animais em lugares anti-higiênicos ou que lhes impeçam a respiração, o movimento ou o descanso, ou os privem de ar ou luz; 
III - obrigar animais a trabalhos excessívos ou superiores ás suas fôrças e a todo ato que resulte em sofrimento para deles obter esforços que, razoavelmente, não se lhes possam exigir senão com castigo;

IV - golpear, ferir ou mutilar, voluntariamente, qualquer órgão ou tecido de economia, exceto a castração, só para animais domésticos, ou operações outras praticadas em beneficio exclusivo do animal e as exigidas para defesa do homem, ou no interêsse da ciência;

V - abandonar animal doente, ferido, extenuado ou mutilado, bem coma deixar de ministrar-lhe tudo o que humanitariamente se lhe possa prover, inclusive assistência veterinária;

VI - não dar morte rápida, livre de sofrimentos prolongados, a todo animal cujo exterminio seja necessário, parar consumo ou não;

VII - abater para o consumo ou fazer trabalhar os animais em período adiantado de gestação;

VIII - atrelar, no mesmo veículo, instrumento agrícola ou industrial, bovinos com equinos, com muares ou com asininos, sendo somente permitido o trabalho etc conjunto a animais da mesma espécie;

IX - atrelar animais a veículos sem os apetrechos indispensáveis, como sejam balancins, ganchos e lanças ou com arreios incompletos incomodas ou em mau estado, ou com acréscimo de acessórios que os molestem ou lhes perturbem o funcionamento do organismo;

$\mathrm{X}$ - utilizar, em serviço, animal cego, ferido, enfermo, fraco, extenuado ou desferrado, sendo que êste último caso somente se aplica a localidade com ruas calçadas;

XI - açoitar, golpear ou castigar por qualquer forma um animal caído sob o veiculo ou com ele, devendo o condutor desprendê-lo do tiro para levantarse;

XII - descer ladeiras com veículos de tração animal sem utilização das respectivas travas, cujo uso é obrigatório;

XIII - deixar de revestir com couro ou material com identica qualidade de proteção as correntes atreladas aos animais de tiro;

XIV - conduzir veículo de terão animal, dirigido por condutor sentado, sem que o mesmo tenha bolaé fixa e arreios apropriados, com tesouras, pontas de guia e retranca;

XV - prender animais atraz dos veículos ou atados ás caudas de outros;

XVI - fazer viajar um animal a pé, mais de 10 quilômetros, sem lhe dar descanso, ou trabalhar mais de 6 horas continuas sem lhe dar água e alimento;

XVII - conservar animais embarcados por mais da 12 horas, sem água e alimento, devendo as emprêsas de transportes providenciar, saibro as necessárias modificações no seu material, dentro de 12 mêses a partir da publicação desta lei;

XVIII - conduzir animais, por qualquer meio de locomoção, colocados de cabeça para baixo, de mãos ou pés atados, ou de qualquer outro modo que lhes produza sofrimento;

XIX - transportar animais em cestos, gaiolas ou veículos sem as proporções necessárias ao seu tamanho e número de cabeças, e sem que o meio de condução em que estão encerrados esteja protegido por uma rêde metálica ou idêntica que impeça a saída de qualquer membro da animal;

XX - encerrar em curral ou outros lugares animais em úmero tal que não lhes seja possível moverem-se livremente, ou deixá-los sem água e alimento mais de 12 horas;

XXI - deixar sem ordenhar as vacas por mais de 24 horas, quando utilizadas na explorado do leite;

XXII - ter animais encerrados juntamente com outros que os aterrorizem ou molestem;

XXIII - ter animais destinados á venda em locais que não reunam as condições de higiene e comodidades relativas; 


\begin{abstract}
XXIV - expor, nos mercados e outros locais de venda, por mais de 12 horas, aves em gaiolas, sem que se faca nestas a devida limpeza e renovação de água e alimento;

XXV - engordar aves mecanicamente;

XXVI - despelar ou depenar animais vivos ou entregá-los vivos á alimentação de outros;

XXVII. - ministrar ensino a animais com maus tratos físicos;

XXVIII - exercitar tiro ao alvo sobre patos ou qualquer animal selvagem exceto sobre os pombos, nas sociedades, clubes de caça, inscritos no Serviço de Caça e Pesca;

XXIX - realizar ou promover lutas entre animais da mesma espécie ou de espécie diferente, touradas e simulacros de touradas, ainda mesmo em lugar privado;

XXX - arrojar aves e outros animais nas casas de espetáculo e exibí-los, para tirar sortes ou realizar acrobacias;

XXXI - transportar, negociar ou cair, em qualquer época do ano, aves insetívoras, pássaros canoros, beija-flores e outras aves de pequeno porte, exceção feita das autorizadas para fins ciêntíficos, consignadas em lei anterior.
\end{abstract}

A Lei $\mathrm{n}^{\circ} 7.643 / 1987$, além de proibir a pesca, ou qualquer forma de molestamento intencional, de toda espécie de cetáceo nas águas jurisdicionais brasileiras, impôs aos infratores a pena de dois a cinco anos de reclusão e multa de 50 (cinquenta) a 100 (cem) Obrigações do Tesouro Nacional (OTN), com perda da embarcação em favor da União, em caso de reincidência (BRASIL, 1987).

Considerando que a destruição e fragmentação dos hábitats naturais são os principais motivos para a perda de biodiversidade, a criação de unidades de conservação, nos moldes da Lei ${ }^{\circ}$ 9.985/2000 (BRASIL, 2000), e de manutenção das áreas protegidas, como as áreas de preservação permanente, nos termos da Lei $\mathrm{n}^{0}$ 12.651/2012 (BRASIL, 2012), incluindo o ecossistema manguezal (CABRAL, 2003), são instrumentos importantes para a manutenção das populações naturais da biodiversidade, incluindo a dos animais (PAZ et al., 2006, 2008).

\title{
CONCLUSÃO
}

Embora seja feita uma breve análise da legislação federal brasileira sob a óptica dos direitos dos animais, observa-se que o corpo normativo, embora, por evidente, essencialmente construído com uma visão antropocêntrica, contém avanços significativos e capazes de tutelar de maneira eficiente, se não todos, pelo menos alguns direitos significativos dos animais.

\section{REFERÊNCIAS}

BRASIL. Decreto $\mathrm{n}^{\circ}$ 24.645, de 10 de julho de 1934. Estabelece medidas de proteção aos animais. Disponível em: <http://www.planalto.gov.br/ ccivil_03/decreto/19301949/D24645impressao.htm>. Acesso em: 24 abr. 2016.

BRASIL. Decreto-Lei n ${ }^{\circ}$ 5.894, de 20 de outubro de 1943. Aprova e baixa o Código de Caça. Disponível em: <http://www.planalto.gov.br/ccivil_03/ Decreto-Lei/19371946/Del5894.htmimpressao.htm>. Acesso em: 24 abr. 2016.

BRASIL. Lei ${ }^{\circ}$ 5.197, de 3 de janeiro de 1967. Dispõe sobre a proteção à fauna e dá outras providências. Disponível em: <http://www.planalto.gov.br/ ccivil_03/leis/L5197.htm>. Acesso em: 24 abr. 2016. 
BRASIL. Lei ${ }^{0}$ 7.643, de 18 de dezembro de 1987. Proíbe a pesca de cetáceo nas águas jurisdicionais brasileiras, e dá outras providências. <http://www.planalto.gov.br/ccivil_03/leis/L7643.htm>. Acesso em: 24 abr. 2016.

BRASIL. Lei $n^{\circ}$ 9.605, de 12 de fevereiro de 1998. Dispõe sobre as sanções penais e administrativas derivadas de condutas e atividades lesivas ao meio ambiente, e dá outras providências. Disponíveis em: <http://www.planalto.gov.br/ ccivil_03/leis/L9605.htm>. Acesso em: 24 abr. 2016.

BRASIL. Lei $n^{\circ}$ 9.985, de 18 de julho de 2000. Regulamenta o art. 225, § $1^{\circ}$, incisos I, II, III e VII da Constituição Federal, institui o Sistema Nacional de Unidades de Conservação da Natureza e dá outras providências. Disponível em: <http://www.planalto.gov.br/ccivil_03/leis/L9985.htm>. Acesso em: 24 abr. 2016.

BRASIL. Lei $n^{\circ}$ 12.651, de 25 de maio de 2012. Dispõe sobre a proteção da vegetação nativa; altera as Leis $\mathrm{n}^{\text {os }}$ 6.938, de 31 de agosto de 1981, 9.393, de 19 de dezembro de 1996, e 11.428, de 22 de dezembro de 2006; revoga as Leis $\mathrm{n}^{\text {os }} 4.771$, de 15 de setembro de 1965, e 7.754, de 14 de abril de 1989, e a Medida Provisória ${ }^{\circ}$ 2.166-67, de 24 de agosto de 2001; e dá outras providências. Disponível em: <http://www.planalto.gov.br/ccivil_03/_ato2011-2014/2012/lei/ L12651compilado.htm>. Acesso em: 24 abr. 2016.

CABRAL, G. J. C. M. O direito do mangue: aspectos jurídicos, científicos e filosóficos aplicados à proteção do ecossistema manguezal. João Pessoa: Sal da Terra, 2003.

CROALL, S.; RANKIN, W. Conheça Ecologia. 1. ed. São Paulo: Proposta Editorial, 1981. (Coleção Conheça, 5).

DUARTE FILHO, F. H.; AGUIAR, J. O. Baleias e ecologistas na Paraíba: uma história do fortalecimento do movimento ambientalista e o debate sobre a crise da economia baleeira (1970-1980). Topoi, v. 15 n. 28, p. 116-142, 2014. http://dx.doi.org/10.1590/2237$101 \mathrm{X} 015028004$

ESCOBAR, M. L.; AGUIAR, J. O.; ZAGUI, P. A. Galos em Combate na Paraíba: o descumprimento da legislação ambiental. Revista Direitos Humanos e Democracia, v. 2, n. 4, p. 143-165, 2014. Disponível em: <https://www.revistas.unijui.edu.br/ index.php/direitoshumanosedemocracia/article/view/2988/3437>. Acesso em: 24 abr. 2016.

FARIAS, T. Introdução ao Direito Ambiental. Belo Horizonte: Del Rey, 2009.

GODINHO, H. T. N. A tutela jurídica da fauna selvagem terrestre: uma abordagem comparada dos ordenamentos português e brasileiro. Curitiba: Juruá, 2011.

HARARI, Y. N. Sapiens: uma breve história da humanidade. 10. ed. Porto Alegre: L\&PM, 2016.

Higginbotham, J.; HigginbothaM, R. Paganismo: uma Introdução da Religião Centrada na Terra. São Paulo: Madras, 2003.

LEVAI, L. F. Direitos dos animais. ed. rev. ampl. atual. Campos do Jordão, Mantiqueira, 2004. 
PAZ, R. J.; FREITAS, G. L.; SOUZA, E. A. Unidades de conservação no Brasil: história e legislação. João Pessoa: Editora Universitária/UFPB, 2006.

PAZ, R. J.; FREITAS, G. L.; SOUZA, E. A. As áreas protegidas na legislação brasileira. In: PAZ, R. J.; FARIAS, T. Gestão de áreas protegidas: processos e casos particulares. João Pessoa: Editora Universitária/UFPB, 2008. p. 21-40. 